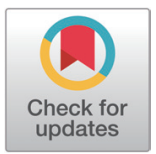

Received: Oct 11, 2021

Revised: Oct 15, 2021

Accepted: Oct 18, 2021

\#These authors contributed equally to this work.

*Corresponding author

Hyeun Bum Kim

Department of Animal Resources

Science, Dankook University, Cheonan

31116, Korea.

Tel: +82-41-550-3653

E-mail: hbkim@dankook.ac.kr

Copyright $\odot 2021$ Korean Society of Animal Sciences and Technology.

This is an Open Access article distributed under the terms of the Creative Commons Attribution

Non-Commercial License (http:// creativecommons.org/licenses/bync/4.0/) which permits unrestricted non-commercial use, distribution, and reproduction in any medium, provided the original work is properly cited.

ORCID

Minji Kim

https://orcid.org/0000-0003-2106-1921 Jae Hyoung Cho

https://orcid.org/0000-0002-1128-3451

Pil-Nam Seong

https://orcid.org/0000-0003-2915-1059

Hyunjung Jung

https://orcid.org/0000-0002-7004-2017

Jin Young Jeong

https://orcid.org/0000-0002-8670-7036

Sheena Kim

https://orcid.org/0000-0002-5410-1347

Hyeri Kim

https://orcid.org/0000-0002-6560-2390

Eun Sol Kim

https://orcid.org/0000-0001-8801-421X

\section{Fecal microbiome shifts by different forms of copper supplementations in growing pigs}

Minji Kim ${ }^{1 \#}$, Jae Hyoung Cho ${ }^{2 \#}$, Pil-Nam Seong ${ }^{1}$, Hyunjung Jung ${ }^{1}$, Jin Young Jeong ${ }^{1}$, Sheena Kim², Hyeri Kim², Eun Sol Kim², Gi Beom Keum², Robin B. Guevarra ${ }^{2}$ and Hyeun Bum Kim ${ }^{2 *}$

${ }^{1}$ Animal Nutrition and Physiology Division, National Institute of Animal Science, Rural Development Administration, Wanju 55365, Korea

${ }^{2}$ Department of Animal Resources Science, Dankook University, Cheonan 31116, Korea

\begin{abstract}
Copper is an essential mineral for pigs, thus it is used as a feed additive in the forms of copper sulfate. Therefore, this study aimed at characterizing the fecal microbiota shifts in pigs as fed by different forms of copper supplementation. 40 growing pigs aged $73 \pm 1$ days with an average weight of $30.22 \pm 1.92 \mathrm{~kg}$ were randomly divided into 5 groups. The control group (CON) fed with basal diet, while treatment groups were fed a basal diet supplemented with $100 \mathrm{ppm} / \mathrm{kg}$ of copper sulfate $\left(\mathrm{CuSO}_{4}\right)$, Cu-glycine complex (CuGly), Cu-amino acid complex (CuAA), and Cu-hydroxy(4methylthio)butanoate chelate complex (CuHMB) for 28 days of trial, respectively. The data presented the comparison between inorganic and organic copper supplementation through gut microbiota in growing pigs. Alpha and Beta diversity anaylsis resulted in copper supplementation did shifted gut microbioal community structure. At the phylum level, Firmicutes and Bacteroidetes were the most abundant phyla at all times regardless of treatment. At the genus level, the relative abundances of Prevotella, Lactobacillus, Megasphaera, and SMB53 of the CuGly and CuHMB groups were significantly higher than those of copper sulfate and basal diet groups. Overall, this study may provide the potential role of organic copper replacing inorganic copper, resulting in increased beneficial bacteria in the pig gut.
\end{abstract}

Keywords: Copper supplementation, Gut heatth, Gut microbiome, Pigs

\section{INTRODUCTION}

Copper $(\mathrm{Cu})$, which is one of the essential trace elements that plays an crucial role in various ways in physiological processes. It is known to perform oxidation-reduction reactions, transport of oxygen and electrons, and protection against oxidative stress [1,2]. Copper in feed is reported to improve body weight gain and feed conversion ratio and reduce the frequency of diarrhea [3]. Copper can be included at growth-promoting levels (i.e, 75 to $250 \mathrm{mg} / \mathrm{kg}$ diet) in diets for weaning and growing pigs to reduce post-weaning diarrhea and improve growth performance [2]. Not only it improves growth performance, but also has an effect on intestinal microbes by enhancing host bacterial resistance [4].

Copper may be provided in sulfate, oxide, or chloride forms, as chelated $\mathrm{Cu}$, or as $\mathrm{Cu}$ 
Gi Beom Keum

https://orcid.org/0000-0001-6006-9577

Robin B. Guevarra

https://orcid.org/0000-0002-4809-1816

Hyeun Bum Kim

https://orcid.org/0000-0003-1366-6090

\section{Competing interests}

No potential conflict of interest relevant to this article was reported.

Funding sources

This work was undertaken with the support of the "Cooperative Research Program for Agriculture Science and Technology Development (Project No. PJ01493601)", Rural Development Administration, Korea.

Acknowledgements

Not applicable.

\begin{abstract}
Availability of data and material Upon reasonable request, the datasets of this study can be available from the corresponding author.
\end{abstract}

\section{Authors' contributions}

Conceptualization: Kim M, Seong PN, Jung $\mathrm{H}$, Jeong JY, Kim HB.

Data curation: Kim M, Cho JH.

Formal analysis: Cho JH, Seong P, Kim H, Keum GB.

Methodology: Cho JH, Guevarra RB.

Software: Kim ES, Keum GB, Guevarra RB.

Validation: Kim S, Kim ES.

Investigation: Cho JH, Jung H, Jeong JY.

Writing - original draft: Kim M, Cho JH, Kim S, Guevarra RB, Kim HB.

Writing - review \& editing: Kim M, Cho JH, Seong PN, Jung $\mathrm{H}$, Jeong JY, Kim S, Kim H, Kim ES, Keum GB, Guevarra RB, Kim HB.

Ethics approval and consent to participate The experimental protocol for this study was reviewed and approved by the Rural Development Administration, Jeonju, Korea (approval Number NIAS-2020-1849). hydroxychloride in order to induce a faster growth and a better resistance to various diseases, which, to a great extent, correlated with the improved metal bio-availability $[5,6]$. Copper sulfate $\left(\mathrm{CuSO}_{4}\right)$ is the most common form of inorganic copper suppplement in animal feeds due to its availability, and its relatively low cost compared with other sources of copper [7], which enhances growth performance and gut health $[8,9]$. On the other hand, organic copper such as copper amino acids, which improve apparent total tract digestibility and retention of copper in pigs by preventing formation of insoluble complexes along the gastrointestinal tract [10]. In addition, copper hydroxylchloride, which is as effective as $\mathrm{CuSO}_{4}$ in enhancing growth rate and feed efficiency in pigs [11], including low toxicity compared to $\mathrm{CuSO}_{4}$ [12]. However, supplementation of copper may result in fecal copper excretion [13]. The increased copper excretion might accumulate in soil and water, resulting in reduction of crop yield and potential toxicity for livestock [13]. Therefore, this study evaluates the effects of different types of copper supplementation on the intestinal microbiome of pigs.

\section{MATERIALS AND METHODS}

\section{Animals, facilities and dietary treatments}

The experimental protocol for this study was reviewed and approved by the Rural Development Administration, Jeonju, Republic of Korea (approval Number NIAS-2020-1849). A total of 40 growing pigs (Duroc $\times$ Landrace $\times$ Yorkshire; Male, $73 \pm 1$ day of old) were alloted to a completely randomized block design. The pigs (average initial body weight of $30.22 \pm 1.92 \mathrm{~kg}$ ) were individually placed in $1.1 \times 3.5 \mathrm{~m}^{2}$ stainless steel metabolism cages in an environmentally controlled room $\left(22 \pm 1^{\circ} \mathrm{C}\right)$. There were 2 pigs per treatments in a cage and 4 replicate cages per treatments. The dietary treatments consisted of $\mathrm{CON}$ (No additional added copper sulfate in diet), $\mathrm{CuSO}_{4}$ (positive control; CON + $100 \mathrm{ppm} / \mathrm{kg}$ copper sulfate), $\mathrm{Cu}$-glycine complex (CuGly; CON + 100 $\mathrm{ppm} / \mathrm{kg}$ of copper with glycine), and $\mathrm{Cu}$-amino acid complex (CuAA; $\mathrm{CON}+100 \mathrm{ppm} / \mathrm{kg}$ of copper with amino acids; Proline, Glutamic acid, Serine, Glycine, Aspartic acid, Arginine, Valine, Leucine, Threonine, Alanine, Lysine, Methionine, Isoleucine, Tryosine, Phenylalanine, Histidine, and Cystine), and $\mathrm{Cu}$-hydroxy(4methylthio)butanoate chelate complex (CuHMB; CON + 100 $\mathrm{ppm} / \mathrm{kg}$ of copper chelate). All diets were formulated to meet or exceed the National Research Council (NRC) (Table 1). Throughout the entire experimental period, pigs had ad libitum access to feed and water.

\section{Sample collections and DNA extraction}

A total of 80 fecal samples were collected directly from the rectum of the 40 pigs before (week 0 ) and after dietary supplementation (week 4) (8 pigs per group: $\mathrm{CON}, \mathrm{CuSO}_{4}, \mathrm{CuGly}, \mathrm{CuAA}$, and $\mathrm{CuHMB}$ ). Total DNA from the feces was extracted from $200 \mathrm{mg}$ of feces per sample using QIAamp Fast DNA Stool Mini Kit (QIAGEN, Hilden, Germany) according to the manufacturer's instructions. The concentrations of DNA were measured using a Colibri Microvolume Spectrometer (Titertek Berthold, Pforzheim, Germany) and samples with OD260/280 ratios of 1.80-2.15 were processed further. The V3 to V4 hypervariable regions of the $16 \mathrm{~S}$ rRNA gene were amplified using the universal primers 341F (5'-TCGTCGGCAGCGTCAGATGTGTATAAGA GACAGCCTACGGGNGGCWGCAG-3') and 805R (5'-GTCTCGTGGGCTCGGAGATG TGTATAAGAGACAGGACTACHVGGGTATCTAATCC-3’). The 16S rRNA gene libray preparation was performed, and MiSeq sequencing of 16S rRNA gene amplicons was conducted using the Illumina MiSeq platform at Macrogen (Seoul, Korea). Briefly, random fragments of DNA samples followed by 5' and 3' adapter ligation was conducted to prepared the sequencing 
Table 1. Ingredients and chemical composition of the experimental diets

\begin{tabular}{|c|c|}
\hline Item & Ratio (\%) \\
\hline \multicolumn{2}{|l|}{ Ingredients } \\
\hline Corn & 64.60 \\
\hline Soybean meal (45\%) & 20.50 \\
\hline Wheat bran & 8.90 \\
\hline Soybean oil & 2.00 \\
\hline Molasses & 1.50 \\
\hline Limestone & 0.75 \\
\hline Tricalcium phosphate & 0.55 \\
\hline L-Lysine & 0.40 \\
\hline Salt & 0.30 \\
\hline Vitamin-mineral premix ${ }^{1)}$ & 0.50 \\
\hline \multicolumn{2}{|l|}{ Calculated composition } \\
\hline Metabolizable energy (kcal/kg) & 3,300 \\
\hline Crude protein & 16.00 \\
\hline Crude fat & 4.80 \\
\hline Lysine & 1.01 \\
\hline Methionine + cysteine & 0.48 \\
\hline Calcium & 0.53 \\
\hline Phosphorus & 0.46 \\
\hline Ash & 4.47 \\
\hline
\end{tabular}

library. Using the Nextera XT Index Kit (Illumina, San Diego, CA, USA), dual indices and Illumina sequencing adapters were attached to the $16 \mathrm{~S}$ rRNA gene amplicons. The concentration of final products was normalized and pooled, using PicoGreen (Turner BioSystems, Sunnyvale, CA, USA), then the verification of the size of libraries was conducted using the TapeStation DNA ScreenTape D1000 (Agilent Technologies, Santa Clara, CA, USA). The polymerase chain reaction (PCR) cycle conditions included a 3 min initial denaturation at $95^{\circ} \mathrm{C}, 8$ amplification cycles $\left(95^{\circ} \mathrm{C}\right.$ for 30 s, $55^{\circ} \mathrm{C}$ for $30 \mathrm{~s}$ and $72^{\circ} \mathrm{C}$ for $30 \mathrm{~s}$ ) and a $5 \mathrm{~min}$ final elongation at $72^{\circ} \mathrm{C}$.

Fecal microbiome analysis (16S rRNA gene sequencing, sequence analysis)

Mothur software was used to remove low-quality sequences from the 16S rRNA gene sequences. Briefly, sequences that did not match the PCR primers were discarded from the demultiplexed sequence reads. To minimize the effects of random sequencing errors, sequences containing ambiguous base calls and sequences with a length of less than $100 \mathrm{bp}$ were trimmed. Chimeric sequences were eliminated using the UCHIME algo-rithm implemented in Mothur. With an operational taxonomic unit (OTU) definition at an identity cutoff of $97 \%$, de novo OTU clustering was conducted using the Quantitative Insights into Microbial Ecology (QIIME) software package (version 1.9.1) [14]. The naïve Bayesian RDP classifier and the Greengenes reference database were used for the taxonomic assignment of the sequences. Beta-diversity was measured using unweighted UniFrac distance metrics using QIIME, which considers community membership (pres-ence or absence of OTUs). Principal coordinate analysis (PCoA) plots were generated based on unweighted UniFrac distance metrics. 


\section{Statistical analysis}

The gut microbiome parameters were calculated using the $\mathrm{R}$ package MicrobiomeAnalystR and GraphPad Prism version 7.00 for Windows (GraphPad Software, CA, USA). Orthogonal contrasts ( $\mathrm{CON}$ vs. other treatments; $\mathrm{CuSO}_{4}$ vs. other treatments) were used to compare the possible relationships between the treatments. A two-way ANOVA was used to confirm the alpha-diversity and taxonomic analysis data. Differences among treatment means were determined using Tukey's test. For a two-sided Welch's $t$-test in the Satistical Analysis of Metagenomic Profiles (STAMP) software v2.1.3 was used to identify significant differences in the relative abundance of micrbial taxa among the five groups. Analysis of similarities (ANOSIM) was used to determine wheter the microbial compositions between the five groups were significantly different or not using QIIME and were based on the unweighted and weighted UniFrac distance metrics. Statistical significance was set a $p<0.05$.

\section{RESULTS}

\section{Summary of DNA sequence data, alpha and beta diversity}

Total DNA was extracted from fecal samples of the pigs, and the extracted DNA was amplified and sequenced through PCR, using primers specific to the V3 to V4 hypervariable regions of the $16 \mathrm{~S}$ rRNA genes. Sequencing of the $16 \mathrm{~S}$ rRNA genes in fecal samples produced a total of 10,761,929 reads, which ranged from 108,083 to 163,252 reads per sample. The average quality score (Phred scores) across all the samples ranged from 32 to 36 . Further data filtering was performed to remove low quality or uninformative data and to improve the downstream statistical analysis. It resulted in $7,325,950$ combined reads from all the samples, with an average reads per sample of 91,574 .

From the fecal samples, the diversity of the microbial coummunities of pigs was measured using: species richness (number of observed OTUs and Chao1) and species evenness (Shannon and Simpson) within a sample (Fig. 1). Among five groups at week 0, the number of observed OTUs ranged from 205-595, Chao1 as 220.75-628.06, Shannon and Simpson 2.05-4.45 to 0.64-0.97, respectively. CuGly group showed the highest number of observed OTUs, Chao1, Shannon, and Simpson indices with mean values of $511.12 \pm 86.56,548.91 \pm 93.21,3.72 \pm 0.72$, and $0.89 \pm$ 0.10 , respectively. At week 4, 442-703 ranging on the number of observed OTUs, 429.77-471.87 in Chao1, Shannon and Simpson 2.52-4.50 to 0.72-0.97, respectively. CuAA group showed the highest number of all indices with mean values of $639.75 \pm 34.16,675.32 \pm 36.38,4.07 \pm 0.29$, and $0.94 \pm 0.02$, respectively. It indicates that supplementation of $\mathrm{CuAA}$ group increased the species richness and diversity in the feces of pigs at week 4 . However, no statistical differences were shown with Shannon and Simpson index at both week 0 and 4. Conversely, CuAA group at week 4 was observed significantly different with observed OTUs and Chao1 as compared to the CON group $(p<0.05)$.

At week 0 , the PCoA plot showed no significant differences of the microbial community among control, positive control and treatment groups as confirmed by ANOSIM, from results of both weighted and unweighted UniFrac distances, ( $p>0.05$, data not shown). Conversely, each group clustered significantly by weeks (week 0 and 4 ) which suggests that the microbial community structure shifts over time regardless of the treatment (Fig. 2).

\section{Taxonomic analysis}

Microbial composition of swine gut with copper supplementation was determined. The relative abundance of different bacterial taxa at the phylum level among the five groups $\left(\mathrm{CON}, \mathrm{CuSO}_{4}\right.$, $\mathrm{CuGly}, \mathrm{CuAA}$, and $\mathrm{CuHMB}$ ) between week 0 and week 4 (Fig. 3). The most common phyla in all 
A

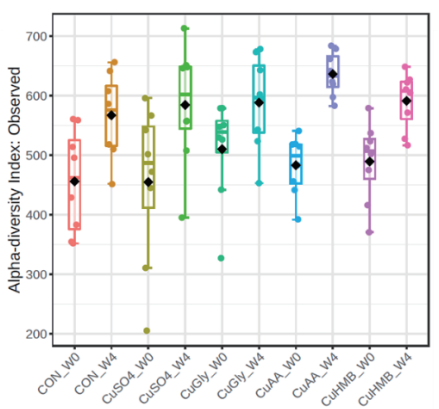

B

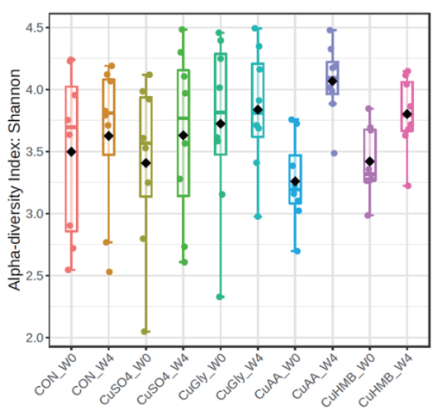

C
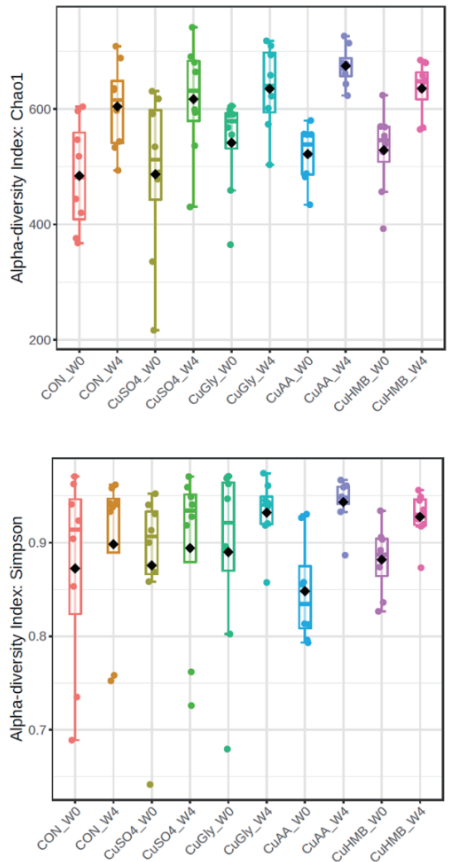

由 CON WO CON_W4 角 CusO4_wo 审 CuSO4_W4 由ugly_wo CuGly_W4 审 CuAa_wo 由UAAW4 CUHMB_wo 审 CuHMB_W4

Fig. 1. Box plots of the alpha diversity indices in gut microbiomes of swine treated with copper supplementation. Species richness were measured using (a) number of observed OTUs and (b) Chao1 diversity index. Species evenness and diversity were measured using (c) Shannon and (d) Simpson divesity indices. Each box represent the interquartile range (IQR) between 25th and 75th percentile, as horizontal line inside the box indicates the median value. Whiskers denotes the lowest and the highest values within 1.5 times from the 25th and 75th quartiles respectively. Boxes are colored according to the treatment group as shown in the legend. WO and W4 indicate week 0 and week 4, respectively. OTU, operational taxonomic unit; CON, basal diet; CuGly, Cu-glycine complex; CuAA, Cu-amino acid complex; CuHMB, Cu-hydroxy(4methylthio) butanoate chelate complex.

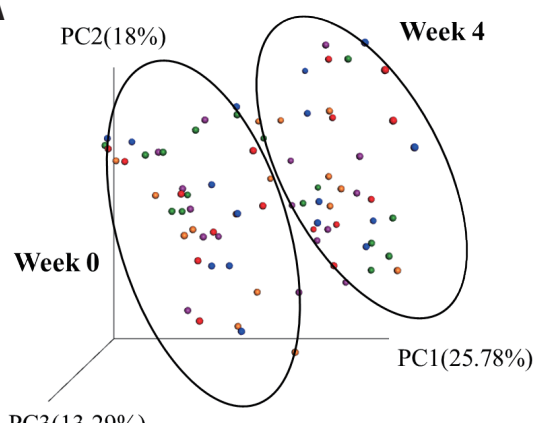

PC3(13.29\%)
B

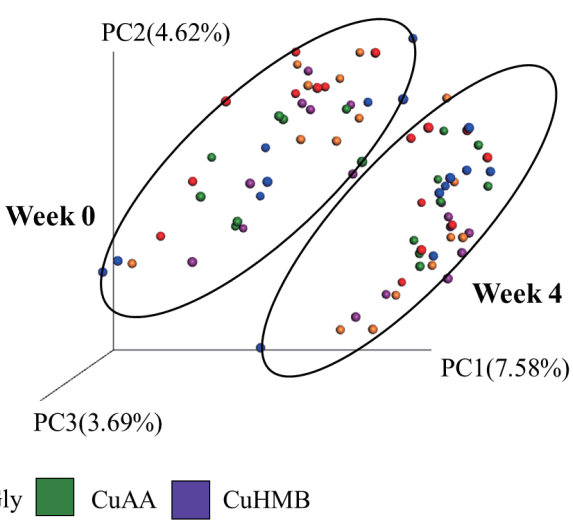

Fig. 2. Principal coordinates analysis (PCoA) plots of copper supplementation in weeks. Week 0 (right) and week 4 (left) group significantly clustered based on weighted (A) and unweighted (B) UniFrac distance metrics (weighted: $p<0.05$, R: 0.300647; unweighted: $p<0.05$, R: 0.341922). CON, basal diet; CuGly, Cuglycine complex; CuAA, Cu-amino acid complex; CuHMB, Cu-hydroxy(4methylthio)butanoate chelate complex.

the samples at both week 0 and week 4 were Firmicutes and Bacteriodetes. At week 0, Firmicutes and Bacteroidetes in each groups were 75.72\%, 14.59\% (CON), 77.50\%, $14.53 \%\left(\mathrm{CuSO}_{4}\right), 71.35 \%$, 
A

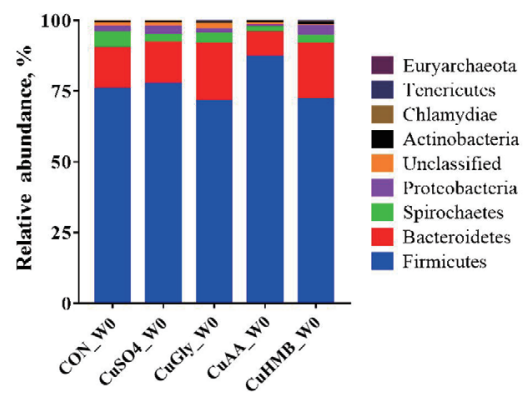

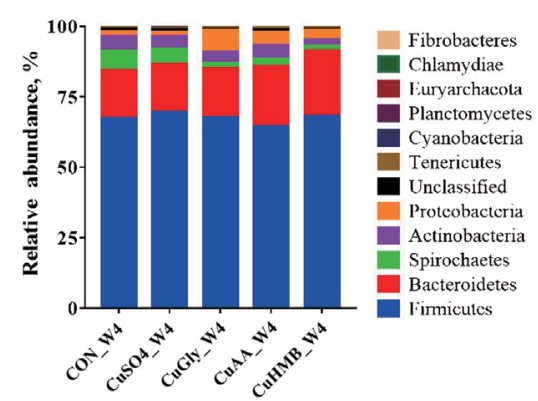

Fig. 3. Gut microbiota composition at the phylum level in pigs with copper supplementation. Bar plots show the relative abundance of taxa at the phylum level at (A) week 0 and (B) week 4 among the five groups CON, basal diet; CuGly, Cu-glycine complex; CuAA, Cu-amino acid complex; CuHMB, Cu-hydroxy(4methylthio) butanoate chelate.

20.31\% (CuGly), 87.09\%, 8.74\% (CuAA), and 71.94\%, 19.82\% (CuHMB), respectively. In addition, the relative abundance of Proteobacteria on $\mathrm{CON}$ group were $2.02 \%$, followed by $\mathrm{CuSO}_{4}$ (2.89\%), CuGly (1.52\%), CuAA (0.94\%), and CuHMB (3.35\%). At week 4, Firmicutes and Bacteroidetes were also the most predominant phyla in all the samples, $\mathrm{CuHMB}$ group having the highest combined relative abundance of $91.39 \%$ followed by $\mathrm{CuSO}_{4}$ (86.53\%), CuAA (85.76\%), CuGly (85.23\%), and CON (84.46\%). Moreover, the relative abundance of Proteobacteria, $\mathrm{CuGly}$ had the highest and $\mathrm{CuSO}_{4}$ had the lowest proportions among 5 groups. These findings were similar to previous studies in swine gut microbiota, indicating that phylum Firmicutes and Bacteroidetes are the major phyla, regardless of copper supplementation treatment.

The relative abundance of different bacterial taxa at the genus level among the five groups (CON, $\mathrm{CuSO}_{4}, \mathrm{CuGly}, \mathrm{CuAA}$, and $\mathrm{CuHMB}$ ) between week 0 and week 4 (Fig. 4). The bacterial genera with counts lower than 5,000 were merged into "Others". At week 0 , the top most predominant classified genera in the fecal microbiota of pigs were Lactobacillus. Lactobacillus with the highest and lowest abundance detected in the CuAA (58.52\%) and CuGly (49.98\%) groups. Nevertheless, the relative abundance of Lactobacillus has decreased on week 4, since other genera increased such as Megasphaera, Prevotella, and SMB53 in all five groups.

A

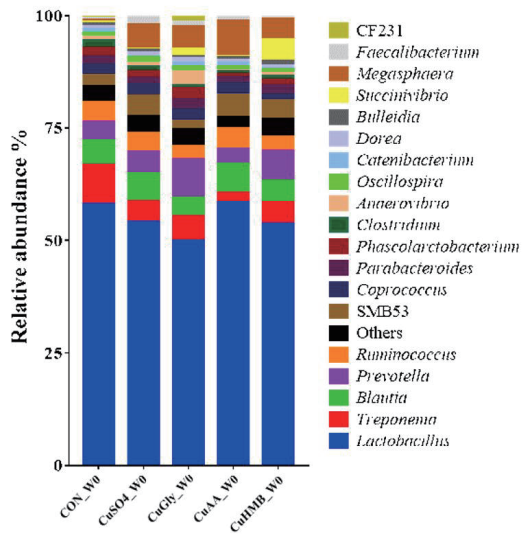

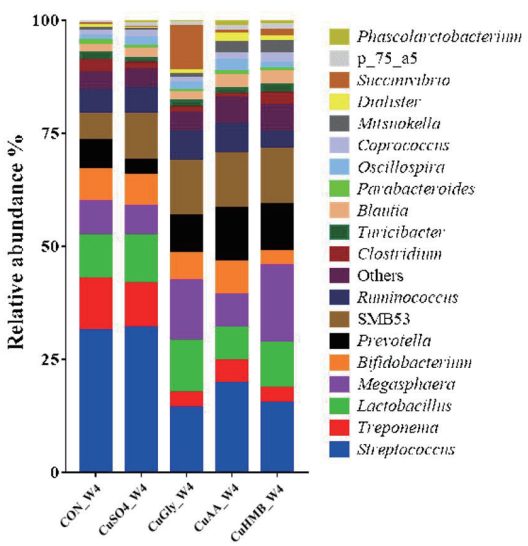

Fig. 4. Gut microbiota composition at the genus level in pigs with copper supplementation. Bar plots show the relative abundance of taxa at the genus level at (A) week 0 and $(B)$ week 4 among the five groups. CON, basal diet; CuGly, Cu-glycine complex; CuAA, Cu-amino acid complex; CuHMB, Cu-hydroxy(4methylthio) butanoate chelate complex. 


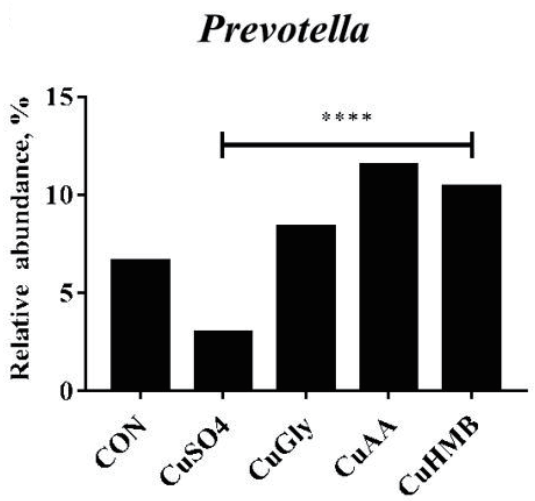

B

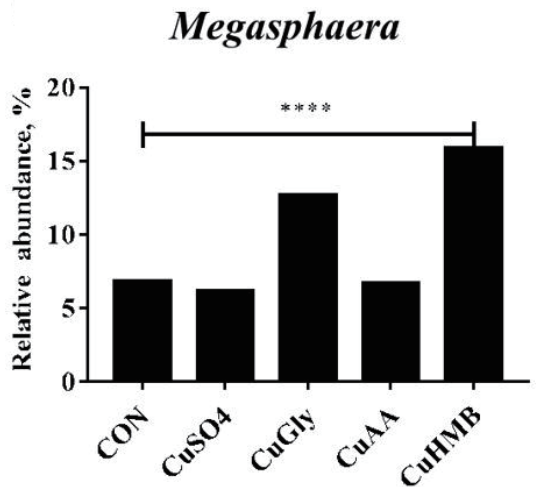

C

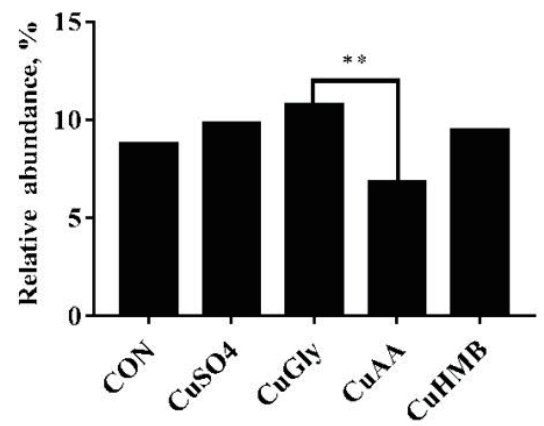

D

SMB53

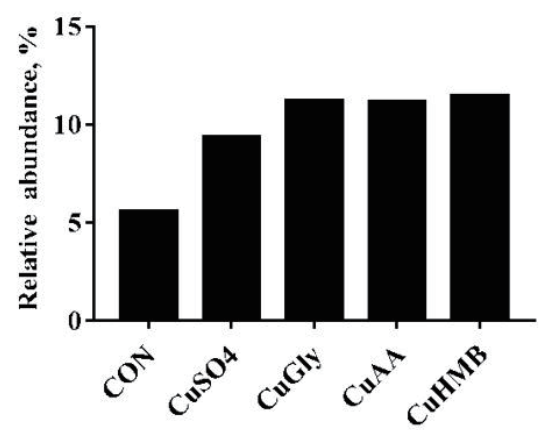

Fig. 5. The bar plot identifying the different taxon between control and copper supplementation treatments. All five groups at the genus (A-D) level at week 4 were examined. All genus showed significantly different $\left({ }^{* *} p<0.01 ;{ }^{* * *} p<0.0001\right)$. CON, basal diet; CuGly, Cu-glycine complex; CuAA, Cu-amino acid complex; CuHMB, Cu-hydroxy(4methylthio)butanoate chelate complex.

At the genus level, Lactobacillus was the most enriched genus in all fecal samples in week 0 (Fig. 4A), Streptococcus in week 4 (Fig. 4B) as followed. 4 genus were significantly different either CON or $\mathrm{CuSO}_{4}$ group in week 4; Prevotella, Lactobacillus, Megasphaera, and SMB53 (Fig. 5). Prevotella, its relative abundance increased significantly in the $\mathrm{CuGly}, \mathrm{CuAA}$, and $\mathrm{CuHMB}(8.35 \%, 11.51 \%$, and $10.41 \%$ ) groups compared to the $\mathrm{CON}$ and $\mathrm{CuSO}_{4}$ group (6.63\% and 2.97\%; Fig. $5 \mathrm{~A}$ ). The relative abundance of Lactobacillus significantly increased from an average of $10.75 \%$ and $9.46 \%$ in the $\mathrm{CuGly}$ and $\mathrm{CuHMB}$ group, whereas its abundance in the CuAA decreased (6.83\%) compared to that in the $\mathrm{CON}$ group (8.77\%; Fig. 5B). Megaspharea showed significantly high relative abundance in $\mathrm{CuGly}$ and $\mathrm{CuHMB}(12.71 \%$ and $15.85 \%)$ groups than other groups (CON; $6.85 \%, \mathrm{CuSO}_{4} ; 6.18 \%$, CuAA; 6.70\%; Fig. 5C). For SMB53, all groups compared to CON group (5.56\%) have increased significantly in realtive abundance $(9.35 \%, 11.20 \%, 11.16 \%$, and $11.44 \%$, respectively; Fig. 5D).

\section{DISCUSSION}

Copper is an essential mineral in pigs with an essnetial cofactor for many cellular enzymes and many biological functions. It promotes bone formation, iron metabolism, enhances immunity and antioxidant capacity $[4,15]$. Copper supplementation $(150-250 \mathrm{mg} \mathrm{Cu} / \mathrm{kg}$ feed) in pig feeds has become popular as alternative to antibiotics due to the ban of antibiotic growth promoters $[16,17]$. Several studies reported that copper supplementation may not only regulate the activities of various enzymes such as digestive and antioxidant enzymes in pigs, but also may regulate the growth 
signalling pathways, feeding and fasting signalling pathways, and hence improve protein deposition and promote bone formation $[18,19]$. However, the overuse of $\mathrm{CuSO}_{4}$ results in an increase of copper content of pig slurry, resulting in copper in soils, which poses a high environmental risk [20]. Not only affecting the swine gut microbiota but also reduces the counts of Streptococci, ureolytic bacteria, and total anaerobes in the feces [4]. In order to reduce the usage of $\mathrm{CuSO}_{4}$, it is recommened to use the alternatives, which is known as organic copper. According to Association of American Feed Control Officials (AAFCO), organic minerals(copper) showed better absorbability, reduced excretion out of the body, stability in the gastrointestinal tract (GIT), and reduced toxicity compared to inorganic minerals such as $\mathrm{CuSO}_{4}$ [21]. Due to the high cost of organic copper compared to $\mathrm{CuSO}_{4}$, further studies are necessary to minimize use of copper in swine diets and prevent copper pollution in the environment.

Formal studies showed the mammalian GIT contains more than 500 bacterial species that would play important roles in the health and disease of the host [22]. The gut microbiota is being indicated to work importantly in the health and growth of animals, including the incidence decrease of infections, inflammations and other immune diseases [23,24]. As the attention to swine gut microbiome has increased, we performed this study to better understand microbial succession and fecal microbiome shifts in the growing pig by supplying different forms of copper for 4 weeks. The relative abundance of Prevotella significantly increased after supplement of $\mathrm{CuAA}$ and $\mathrm{CuHMB}$ groups compared to $\mathrm{CuSO}_{4}$ group. Generally, Prevotella is well known to produce enzymes, such as $\beta$-glucanase, mannase and xylase [25] which take part in degrading polysaccharides originated from plant cell walls into short-chain fatty acids (SCFAs), resulting in utilization as an energy source, including prevention of gut inflammation [26,27]. CuGly group has been identified as the highest relative abudance of Lactobacillus among all treatments of copper supplementation. Lactobacillus is the well-known bacterium to utilize carbohydrates with various genes encoded with a wide range of functional capacities related with carbohydrate transport and utilization [28]. CuGly and CuHMB groups had significantly higher relative abundance of Megaspharea, alike Prevotella, it can also degrade carbohydrates efficiently by converting into SCFAs, resulting in producing energy source for growth performance [29,30]. For SMB53, which belongs to the Clostridiaceae family, all copper supplementaion groups showed significantly higher relative abundance compared to $\mathrm{CON}$ and $\mathrm{CuSO}_{4}$ group. Previous studies indicated that $\mathrm{SMB} 53$ genes are related with immune system [31], and bile acid synthesis regulation $[32,33]$. Our results suggests that these significantly enriched genera may play a role in swine gut microbiota modulation which could contribute in energy production for enhancing growth performance, and regulating immune system, preventing from gut inflammation and other infections related to intestines.

Since there are some doubts mentioning about the structural integrity (and consequently metal bio-availability) of amino-acid chelates at low $\mathrm{pH}$ values of the first digestive tract, a new chelating ligand which is available to provide metal chelates sufficiently stable at low $\mathrm{pH}$ values is needed $[34,35]$. The supplementation of $\mathrm{CuHMB}$, previous studies showed that it indicated more stable at low $\mathrm{pH}$ values than the corresponding chelates with amino-acids $[36,37]$ with higher bioavailability as compared with the $\mathrm{CuSO}_{4}$ [38].

In this study, we evaluated the changes in the intestinal microbial communities induced by different forms of dietary copper supplements. It has been revealed that various types of organic copper supplements shift the intestinal microbiota in growing pigs and may provide insights into the development of feed additives to improve growth performance in swine. 


\section{CONCLUSION}

The different forms of copper supplementation showed varying effects on the composition of the gut microbiota compared to the basal $\operatorname{diet}(\mathrm{CON})$ and copper sulfate $\left(\mathrm{CuSO}_{4}\right)$ supplementation in growing pigs. $\mathrm{CuGly}$ and $\mathrm{CuHMB}$ could enhance beneficial microbiota that contribute to the degradation of polysaccharides and carbohydrates of plant cell walls into SCFAs, which can be converted to an energy source and prevent intestinal inflammation, resulting in improved growth performance.

\section{REFERENCES}

1. Manto M. Abnormal copper homeostasis: mechanisms and roles in neurodegeneration. Toxics. 2014;2:327-45. https://doi.org/10.3390/toxics2020327

2. Espinosa CD, Stein HH. Digestibility and metabolism of copper in diets for pigs and influence of dietary copper on growth performance, intestinal health, and overall immune status: a review. J Anim Sci Biotechnol. 2021;12:13. https://doi.org/10.1186/s40104-020-00533-3

3. Das AK, Chowdhury NR, Nanda PK, Dandapat P, Batabyal S, Biswas S, et al. Role of gut microbiota modulation in health and production of pigs. Indian J Anim Health. 2020;59:75-88. https://doi.org/10.36062/ijah.59.2SPL.2020.75-88

4. Zhang Y, Zhou J, Dong Z, Li G, Wang J, Li Y, et al. Effect of dietary copper on intestinal microbiota and antimicrobial resistance profiles of Escherichia coli in weaned piglets. Front Microbiol. 2019;10:2808. https://doi.org/10.3389/fmicb.2019.02808

5. Espinosa CD, Fry RS, Usry JL, Stein HH. Copper hydroxychloride improves growth performance and reduces diarrhea frequency of weanling pigs fed a corn-soybean meal diet but does not change apparent total tract digestibility of energy and acid hydrolyzed ether extract.J Anim Sci. 2017;95:5447-54. https://doi.org/10.2527/jas2017.1702

6. Yang ZW, Aygul N, Liu XR, Zhao SS, Zhao WQ, Yang SL. Structure of copper chelate of 2-hydroxy-4-methylthiobutanoic acid as trace mineral additive in animal feeding. Chinese J Struct Chem. 2015;34:147-53. https://doi.org/10.14102/j.cnki.0254-5861.2011-0490

7. Shelton NW, Tokach MD, DeRouchey JM, Hill GM, Amachawadi RG, Nagaraja TG, et al. Effects of copper sulfate and zinc oxide on weanling pig growth and plasma mineral levels. Kansas Agric Exp Stn Res Rep. 2009;0:65-72. https://doi.org/10.4148/2378-5977.6785

8. Pérez VG, Waguespack AM, Bidner TD, Southern LL, Fakler TM, Ward TL, et al. Additivity of effects from dietary copper and zinc on growth performance and fecal microbiota of pigs after weaning.J Anim Sci. 2011;89:414-25. https://doi.org/10.2527/jas.2010-2839

9. Stahly TS, Cromwell GL, Monegue HJ. Effects of the dietary inclusion of copper and(or) antibiotics on the performance of weanling pigs. J Anim Sci. 1980;51:1347-51. https://doi. org/10.2527/jas1981.5161347x

10. Liu Y, Ma YL, Zhao JM, Vazquez-Añón M, Stein HH. Digestibility and retention of zinc, copper, manganese, iron, calcium, and phosphorus in pigs fed diets containing inorganic or organic minerals.J Anim Sci. 2014;92:3407-15. https://doi.org/10.2527/jas.2013-7080

11. Cromwell GL, Lindemann MD, Monegue HJ, Hall DD, Orr DE Jr. Tribasic copper chloride and copper sulfate as copper sources for weanling pigs. J Anim Sci. 1998;76:118-23. https:// doi.org/10.2527/1998.761118x

12. Miles RD, O'Keefe SF, Henry PR, Ammerman CB, Luo XG. The effect of dietary supplementation with copper sulfate or tribasic copper chloride on broiler performance, relative copper bioavailability, and dietary prooxidant activity. Poult Sci. 1998;77:416-25. https://doi. 
org/10.1093/ps/77.3.416

13. Lin G, Guo Y, Liu B, Wang R, Su X, Yu D, et al. Optimal dietary copper requirements and relative bioavailability for weanling pigs fed either copper proteinate or tribasic copper chloride. J Anim Sci Biotechnol. 2020;11:54. https://doi.org/10.1186/s40104-020-00457-y

14. Kopylova E, Noé L, Touzet H. SortMeRNA: fast and accurate filtering of ribosomal RNAs in metatranscriptomic data. Bioinformatics. 2012;28:3211-17. https://doi.org/10.1093/bioinformatics/bts611

15. Gao Y, Yang W, Che D, Adams S, Yang L. Advances in the mechanism of high copper diets in restraining pigs growth.J Anim Physiol Anim Nutr. 2020;104:667-78. https://doi.org/10.1111/ jpn.13213

16. Adams S, Che D, Hailong J, Zhao B, Rui H, Danquah K, et al. Effects of pulverized oyster mushroom (Pleurotus ostreatus) on diarrhea incidence, growth performance, immunity, and microbial composition in piglets. J Sci Food Agric. 2019;99:3616-27. https://doi.org/10.1002/ jsfa.9582

17. Che D, Adams S, Wei C, Gui-Xin Q, Atiba EM, Hailong J. Effects of Astragalus membranaceus fiber on growth performance, nutrient digestibility, microbial composition, VFA production, gut $\mathrm{pH}$, and immunity of weaned pigs. MicrobiologyOpen. 2019;8:e00712. https://doi. org/10.1002/mbo3.712

18. Chen Z, Mayer LM, Weston DP, Bock MJ, Jumars PA. Inhibition of digestive enzyme activities by copper in the guts of various marine benthic invertebrates. Environ Toxicol Chem. 2002;21:1243-8. https://doi.org/10.1002/etc.5620210618

19. Kumar J, Sathua KB, Flora SJS. Chronic copper exposure elicit neurotoxic responses in rat brain: assessment of 8-hydroxy-2-deoxyguanosine activity, oxidative stress and neurobehavioral parameters. Cell Mol Biol. 2019;65:27-35. https://doi.org/10.14715/cmb/2019.65.1.5

20. Jondreville C, Revy PS, Jaffrezic A, Dourmad JY. Copper in pig nutrition: essential trace element, growth promoter, and its potential adverse effects on human nutrition and environment. Prod Anim. 2002;15:247-65.

21. Concarr MJ, O'Rourke R, Murphy RA. The effect of copper source on the stability and activity of $\alpha$-tocopherol acetate, butylated hydroxytoulene and phytase. SN Appl Sci. 2021;3:564. https://doi.org/10.1007/s42452-021-04563-y

22. Kim HB, Isaacson RE. The pig gut microbial diversity: understanding the pig gut microbial ecology through the next generation high throughput sequencing. Vet Microbiol. 2015;177:242-51. https://doi.org/10.1016/j.vetmic.2015.03.014

23. Schokker D, Zhang J, Zhang L, Vastenhouw SA, Heilig HGHJ, Smidt H, et al. Early-life environmental variation affects intestinal microbiota and immune development in new-born piglets. PLOS ONE. 2014;9:e100040. https://doi.org/10.1371/journal.pone.0100040

24. Mulder IE, Schmidt B, Stokes CR, Lewis M, Bailey M, Aminov RI, et al. Environmentally-acquired bacteria influence microbial diversity and natural innate immune responses at gut surfaces. BMC Biol. 2009;7:79. https://doi.org/10.1186/1741-7007-7-79

25. Flint HJ, Bayer EA. Plant cell wall breakdown by anaerobic microorganisms from the mammalian digestive tract. Ann N Y Acad Sci. 2008;1125:280-8. https://doi.org/10.1196/annals.1419.022

26. Guevarra RB, Hong SH, Cho JH, Kim BR, Shin J, Lee JH, et al. The dynamics of the piglet gut microbiome during the weaning transition in association with health and nutrition.J Anim Sci Biotechnol. 2018;9:54. https://doi.org/10.1186/s40104-018-0269-6

27. Megahed A, Zeineldin M, Evans K, Maradiaga N, Blair B, Aldridge B, et al. Impacts of environmental complexity on respiratory and gut microbiome community structure and diversity in 
growing pigs. Sci Rep. 2019;9:13773. https://doi.org/10.1038/s41598-019-50187-z

28. Cai H, Thompson R, Budinich MF, Broadbent JR, Steele JL. Genome sequence and comparative genome analysis of Lactobacillus casei: insights into their niche-associated evolution. Genome Biol Evol. 2009;1:239-57. https://doi.org/10.1093/gbe/evp019

29. Wang X, Tsai T, Deng F, Wei X, Chai J, Knapp J, et al. Longitudinal investigation of the swine gut microbiome from birth to market reveals stage and growth performance associated bacteria. Microbiome. 2019;7:109. https://doi.org/10.1186/s40168-019-0721-7

30. Shetty SA, Marathe NP, Lanjekar V, Ranade D, Shouche YS. Comparative genome analysis of Megasphaera sp. reveals niche specialization and its potential role in the human gut. PLOS ONE. 2013;8:e79353. https://doi.org/10.1371/journal.pone.0079353

31. Crespo-Piazuelo D, Migura-Garcia L, Estellé J, Criado-Mesas L, Revilla M, Castelló A, et al. Association between the pig genome and its gut microbiota composition. Sci Rep. 2019;9:8791. https://doi.org/10.1038/s41598-019-45066-6

32. Khan TJ, Ahmed YM, Zamzami MA, Mohamed SA, Khan I, Baothman OAS, et al. Effect of atorvastatin on the gut microbiota of high fat diet-induced hypercholesterolemic rats. Sci Rep. 2018;8:662. https://doi.org/10.1038/s41598-017-19013-2

33. Li T, Chiang JYL. Bile acids as metabolic regulators. Curr Opin Gastroenterol. 2015;31:15965. https://doi.org/10.1097/MOG.0000000000000156

34. Pastore P, Gallina A, Lucaferro P, Magno F. Cu(II)-amino acid and $\mathrm{Cu}(\mathrm{II})$-peptide chelates in animal feeding: a semi-quantitative approach to characterize the commercial products and the limits of their structural integrity. Analyst. 1999;124:837-42. https://doi.org/10.1039/a901489f

35. Cao J, Henry PR, Guo R, Holwerda RA, Toth JP, Littell RC, et al. Chemical characteristics and relative bioavailability of supplemental organic zinc sources for poultry and ruminants. J Anim Sci. 2000;78:2039-54. https://doi.org/10.2527/2000.7882039x

36. Predieri G, Tegoni M, Cinti E, Leonardi G, Ferruzza S. Metal chelates of 2-hydroxy-4-methylthiobutanoic acid in animal feeding: preliminary investigations on stability and bioavailability. J Inorg Biochem. 2003;95:221-4. https://doi.org/10.1016/S0162-0134(03)00067-9

37. Predieri G, Elviri L, Tegoni M, Zagnoni I, Cinti E, Biagi G, et al. Metal chelates of 2-hydroxy-4-methylthiobutanoic acid in animal feeding: part 2: further characterizations, in vitro and in vivo investigations. J Inorg Biochem. 2005;99:627-36. https://doi.org/10.1016/j.jinorgbio.2004.11.011

38. Sun Q, Guo Y, Li J, Zhang T, Wen J. Effects of methionine hydroxy analog chelated $\mathrm{Cu} / \mathrm{Mn} /$ $\mathrm{Zn}$ on laying performance, egg quality, enzyme activity and mineral retention of laying hens. J Poult Sci. 2012;49:20-5. https://doi.org/10.2141/jpsa.011055 